Cite this article as: Chirichilli I, Irace F, Weltert L, Tsuda K, Scaffa R, Salica A et al. Morphological modification of the aortic annulus in tricuspid and bicuspid valves after aortic valve reimplantation: an electrocardiography-gated computed tomography study. Eur J Cardiothorac Surg 2019; doi:10.1093/ejcts/ezz065.

\title{
Morphological modification of the aortic annulus in tricuspid and bicuspid valves after aortic valve reimplantation: an electrocardiography-gated computed tomography study ${ }^{\dagger}$
}

\author{
Ilaria Chirichilli ${ }^{\mathrm{a}}$, Francesco Irace ${ }^{\mathrm{a}}$, Luca Weltert ${ }^{\mathrm{a}}$, Kazumasa Tsuda $^{\mathrm{b}}$, Raffaele Scaffa ${ }^{\mathrm{a}}$, Andrea Salica ${ }^{\mathrm{a}}$, \\ Nicola Galea ${ }^{c}$ and Ruggero De Paulis ${ }^{\mathrm{a}, *}$
}

\footnotetext{
a Department of Cardiac Surgery, European Hospital, Rome, Italy

b First Department of Surgery, Hamamatsu University School of Medicine, Hamamatsu, Japan

c Department of Radiological, Oncological and Pathological Sciences, Sapienza University of Rome, Rome, Italy

* Corresponding author. Department of Cardiac Surgery, European Hospital, Via Portuense 700, 00149 Rome, Italy. Tel: +39-06-65975223; e-mail: rdepaulis58@gmail.com (R. De Paulis).
}

Received 16 October 2018; received in revised form 2 February 2019; accepted 7 February 2019

\section{Key question}

How does reimplantation of the aortic valve modify the morphology of the aortic annulus in the tricuspid aortic valve (TAV) and the bicuspid aortic valve (BAV)?

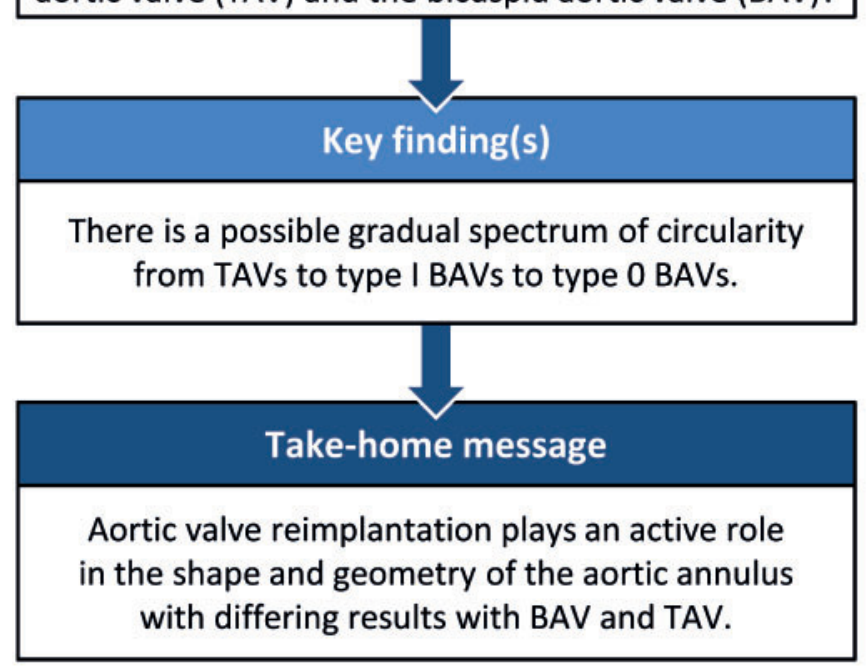

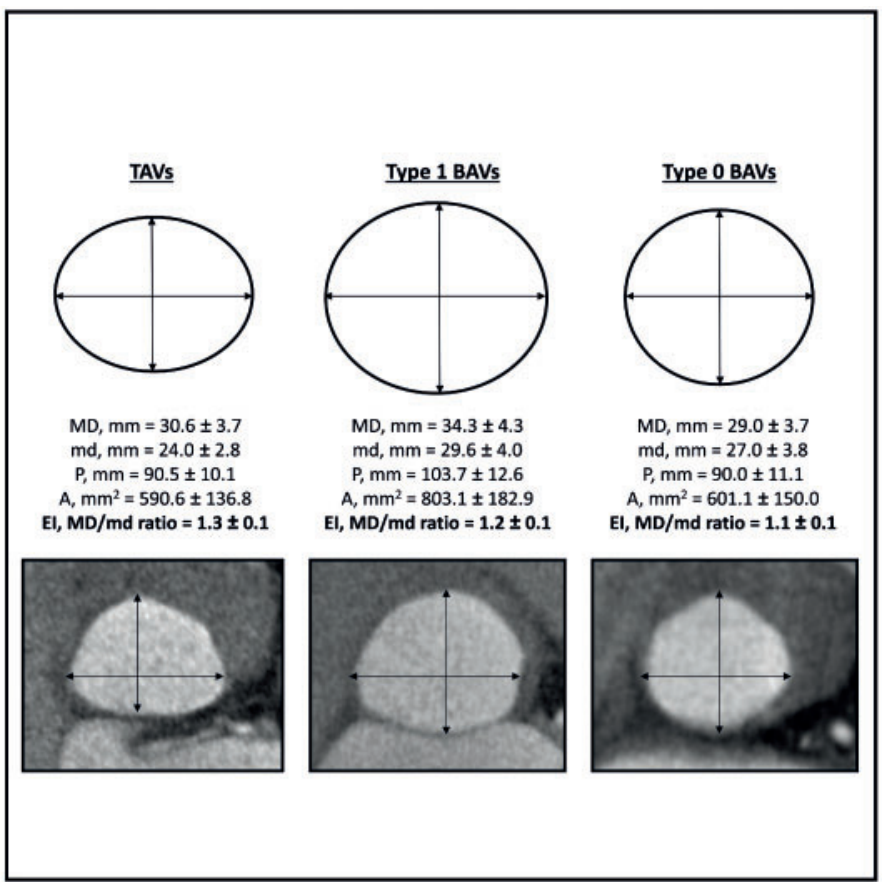

\begin{abstract}
OBJECTIVES: Aortic valve-sparing operations have been shown to produce fewer valve-related complications than valve replacement. The aortic root is a morphological and functional unit in which the annulus plays an important role on dynamism, shape and geometry of the valve with different results in bicuspid aortic valves (BAVs) or tricuspid aortic valves (TAVs). The aim is to evaluate the differences in the size and shape of the aortic annulus between native BAVs and TAVs using ECG-gated computed tomography (CT) after a reimplantation procedure.
\end{abstract}

METHODS: We selected 35 patients scheduled for aortic valve reimplantation who underwent good-quality preoperative and postoperative ECG-gated contrast-enhanced CT scan of the aortic root. Twenty-three patients had TAV, 8 patients type 1 BAV and 4 patients type 0 BAV. 
Major diameter and minor diameter, perimeter (P) and area (A) were measured. The shape of the aortic annulus was considered 'circular' or 'elliptic' according to the Ellipticity Index. We also selected a subgroup of 18 patients (9 TAVs and 9 BAVs) to evaluate annular shape and size variations through the cardiac cycle and to study the expansibility both in the preoperative and in the postoperative phases.

RESULTS: Preoperative CT scans showed an elliptic shape of TAVs (Ellipticity Index 1.3 \pm 0.1 ), a circular shape of type 0 BAVs (1.1 \pm 0.1 ) and an intermediate behaviour of type $1 \mathrm{BAVs}$, suggesting a possible gradual spectrum of circularity from TAVs to type 1 BAVs to type 0 BAVs. Postoperative CT scans did not show any significant difference in annular shape among the 3 groups, which demonstated a similar roundness, obviating the preoperative differences. Analysing the expansibility of the aortic annulus during the cardiac cycle, we observed that it was completely absent in the preoperative phase in BAVs, while in the postoperative phase, both TAVs and BAVs showed a small but similar expansibility after the annular reduction.

CONCLUSIONS: There is a possible gradual spectrum in terms of shape, from native TAVs, to type 1 BAVS to type 0 BAVs. These differences are eliminated in the postoperative phase, suggesting an active role of the annuloplasty on the geometry of the aortic annulus. The preoperative analysis showed a complete inelasticity of BAVs, which was partly restored in the postoperative phase.

Keywords: Aortic annular shape $\cdot$ Bicuspid aortic valve $\cdot$ Tricuspid aortic valve $•$ Aortic annular expansibility $•$ Aortic valve reimplantation

\section{INTRODUCTION}

The effort to better understand and reproduce aortic valvesparing operations is based on the demonstrated principle of fewer valve-related complications as compared to aortic valve replacement procedures [1]. Stability and reproducibility of aortic valve repair are improving, thanks to a fixed geometric annuloplasty [2-6]. In particular, the reimplantation procedure allows at the same time aortic root replacement and aortic annulus stabilization, guaranteeing stable and long-term results [7, 8]. Specific shape features of aortic annulus were identified both in bicuspid aortic valves (BAVs) and in tricuspid aortic valves (TAVs) by previous studies, even if they are still under debate [9-11]. The purpose of this study was to assess the effective modification in size and shape of the aortic annulus after the aortic valve reimplantation procedure. In particular, we focused on shape modifications and relative differences between native BAVs and TAVs.

\section{MATERIALS AND METHODS}

From October 2014 to July 2018, we selected 35 patients scheduled for aortic valve reimplantation at European Hospital of Rome, who underwent good-quality preoperative and postoperative ECG-gated contrast-enhanced computed tomography (CT) scan of the aortic root, performed with an adequate heart rate to minimize possible artefacts. The CT protocol included a ECGretrospective contrast-enhanced $\mathrm{CT}$ scan of the entire thoracic aorta after injection of a bolus of $70-90 \mathrm{ml}$ of iomeprol $400 \mathrm{mg}$ I/dl (Iomeron 400, Bracco, Milan, Italy) at a flow rate of $5 \mathrm{ml} / \mathrm{s}$, followed by a $30-\mathrm{ml}$ saline flush, using a 64-slice CT scanner (Brilliance 64, Philips). CT data sets were reconstructed with a slice thickness of $1 \mathrm{~mm}$ (reconstruction increment $0.5 \mathrm{~mm}$ ) every $10 \%$ steps of the R-R interval (from $0 \%$ to $90 \%$ ) using a mediumsmooth convolution algorithm, and an image matrix of $512 \times 512$ pixels. Dedicated multiplanar planes have been reconstructed applying the double oblique view in order to obtain an axial plane, perpendicular to the long axis of aortic root. The axial image passing through the aortic annulus was identified below the aortic valve at the level of the ventricular-aortic junction. We identified the aortic annulus by the plane passing through the nadir of the 3 cusps. Major diameter and minor diameter, perimeter $(P)$ and area $(A)$ in diastole were measured. The shape of the aortic annulus was considered 'circular' or 'elliptic' according to the Ellipticity Index (El) defined as a major diameter/minor diameter ratio: a value $\geq 1.1$ was considered 'elliptic'. Table 1 summarizes the preoperative data of these patients. The patients were predominantly men $(n=31 ; 89 \%)$, with a mean age of $51.1 \pm 14$ years (range $24-77$ years). A TAV was present in 23 patients (66\%) and a bicuspid valve was present in 12 patients (34\%) (4 type-0 BAV and 8 type-1 BAV) according to the Sievers Classification [12]. Associated pathologies included: Marfan syndrome in 4 patients (11\%), type A aortic dissection in 2 patients (6\%) and aortic arch involvement in 2 patients (6\%). Preoperative echocardiography findings showed a mean left ventricular ejection fraction of $60 \pm 6 \%$; none-to-mild aortic regurgitation ( $\leq 2+)$ was evident in 29 patients (83\%); and moderate-to-severe aortic regurgitation $(\geq 3+)$ in 6 patients $(17 \%)$. The mean aortic root diameter was $49.8 \pm 4.2 \mathrm{~mm}$. Two patients had concomitant moderate mitral regurgitation, 1 coronary disease and 1 previous cardiac surgery.

Moreover, we selected a subgroup of 18 patients ( 9 TAVs and 9 BAVs) who underwent good-quality preoperative and postoperative CT scan, both in systole and in diastole, to assess annular shape and size variations through the cardiac cycle, and evaluate its expansibility both in the preoperative and in the postoperative phases. In these 18 patients, image series were acquired at $30 \%$ and $70 \%$ of the cardiac cycle and were therefore considered 'systolic' or 'diastolic' sequences, respectively.

The surgical technique has been previously described; it has been standardized and did not undergo significant modifications during the study period $[8,13]$. In brief, after the sinuses are excised and the coronary button detached, the valve is inspected for evaluation of leaflet quality. Once the valve is considered suitable to be spared, the root is accurately dissected down to the annulus. Dissection is conducted with particular care to go as deep as possible along the whole circumference of the annulus. Adding $5 \mathrm{~mm}$ to the annulus as measured using a Hegar dilator is used to choose the proper conduit size. Next, to adapt the graft to the specific patient's anatomy, the length of each commissure is reported onto the graft from the sinotubular junction down, ensuring that upon implantation, the top of the commissure will correspond to the level of the new sinotubular junction. Then a series of pledgeted sutures (usually between 6 and 9 sutures) are placed circumferentially and horizontally from inside out at the level of the aortic annulus. Care is taken to pass these sutures 1-2 $\mathrm{mm}$ below the annulus, avoiding any distortion or interfering with the normal movement of the leaflets. These sutures are then passed at the established level of the Valsalva graft and used to anchor it to the annulus. The commissures are then pulled inside 
Table 1: Preoperative clinical data, echocardiographic and CT findings of all patients

\begin{tabular}{|c|c|}
\hline Characteristics & Results \\
\hline Number of patients & 35 \\
\hline \multicolumn{2}{|l|}{ Age (years) } \\
\hline Mean & $51.1 \pm 14$ \\
\hline Range & 24-77 \\
\hline Male sex, $n(\%)$ & $31(89)$ \\
\hline Height $(\mathrm{cm})$, mean $\pm S D$ & $181.3 \pm 9.3$ \\
\hline Weight $(\mathrm{kg})$, mean $\pm \mathrm{SD}$ & $85.9 \pm 16.6$ \\
\hline Body surface area $\left(\mathrm{m}^{2}\right)$, mean $\pm S D$ & $2.05 \pm 0.2$ \\
\hline Bicuspid aortic valve, $n(\%)$ & $12(34)$ \\
\hline Type 1 & $8(67)$ \\
\hline L-R & $7(87)$ \\
\hline R-NC & $1(12)$ \\
\hline Type 0 & $4(33)$ \\
\hline Tricuspid aortic valve, $n(\%)$ & $23(66)$ \\
\hline Marfan syndrome, $n(\%)$ & $4(11)$ \\
\hline Type A aortic dissection, $n(\%)$ & $2(6)$ \\
\hline Previous cardiac surgery, $n(\%)$ & $1(3)$ \\
\hline Aortic arch involvement, $n(\%)$ & $2(6)$ \\
\hline Left ventricular ejection fraction (\%), mean \pm SD & $60 \pm 6$ \\
\hline \multicolumn{2}{|l|}{ Aortic regurgitation, $n(\%)$} \\
\hline 0 & $8(23)$ \\
\hline $1+$ & $13(37)$ \\
\hline $2+$ & $8(23)$ \\
\hline $3+$ & $3(9)$ \\
\hline $4+$ & $3(9)$ \\
\hline Eccentric jet of $A R, n(\%)$ & $6(17)$ \\
\hline Left ventricle end-systolic volume $(\mathrm{ml})$, mean \pm SD & $48 \pm 21.5$ \\
\hline Left ventricle end-diastolic volume (ml), mean \pm SD & $120.3 \pm 42.3$ \\
\hline Left ventricle end-systolic diameter $(\mathrm{mm})$, mean \pm SD & $36.5 \pm 5.5$ \\
\hline Left ventricle end-diastolic diameter $(\mathrm{mm})$, mean \pm SD & $53.5 \pm 5.2$ \\
\hline Mitral regurgitation $>2+, n(\%)$ & $2(6)$ \\
\hline Aortic annulus (mm), mean $\pm S D$ & $26.5 \pm 3.3$ \\
\hline Valsalva sinus $(\mathrm{mm})$, mean $\pm S D$ & $49.8 \pm 4.2$ \\
\hline Sinotubular junction $(\mathrm{mm})$, mean \pm SD & $44.6 \pm 6.7$ \\
\hline Ascending aorta (mm) & $46.8 \pm 7.6$ \\
\hline Mean EuroSCORE II (\%), mean \pm SD & $2.3 \pm 1.0$ \\
\hline
\end{tabular}

CT: computed tomography; SD: standard deviation.

the graft and fixed at the new sinotubular junction. The valve remnants are then sutured to the graft using 3 continuous $4 / 0$ prolene sutures. Coronary ostia are sutured onto the corresponding sinus. Suture of the graft to the distal aorta completes the procedure. The technique works equally well in cases of bicuspid valve where the graft will naturally expand into a 2-sinus configuration. The Valsalva graft characteristics have also been described in detail in several previous publications $[13,14]$.

Table 2 describes the operative data. Six patients received a combined procedure ( 3 mitral valve repair, 1 coronary bypass graft and 2 aortic arch intervention). The mean graft conduit size was $30.8 \pm 1.4 \mathrm{~mm}$. Seventeen patients (49\%) had adjunct aortic cusp plication. In BAV patients, the mean number of used stitches for the annuloplasty was $8.1 \pm 0.9$ (range 7-10); in TAV patients, the mean number was $6.3 \pm 0.9$ (range 6-9).

The study received ethical approval by the local committee.

\section{Statistical analysis}

All data were entered into the Hospital Clinic File System (Clinic Data Pro 4., System Line, Empoli, Italy) at the time of surgery, images of CT scans were processed from the PACS System
Table 2: Operative data

\begin{tabular}{|c|c|}
\hline Variables & Results \\
\hline Graft diameter-overall $(\mathrm{mm})$, mean $\pm S D$ & $30.8 \pm 1.5$ \\
\hline $32, n(\%)$ & $19(54)$ \\
\hline $30, n(\%)$ & $11(31)$ \\
\hline $28, n(\%)$ & $5(14)$ \\
\hline Graft diameter-TAVs $(\mathrm{mm})$, mean $\pm S D$ & $30.4 \pm 1.5$ \\
\hline $32, n(\%)$ & $9(39)$ \\
\hline $30, n(\%)$ & $10(43)$ \\
\hline $28, n(\%)$ & $4(17)$ \\
\hline Graft diameter $-B A V s(\mathrm{~mm})$, mean $\pm S D$ & $31.5 \pm 1.2$ \\
\hline $32, n(\%)$ & $10(83)$ \\
\hline $30, n(\%)$ & $1(8)$ \\
\hline $28, n(\%)$ & $1(8)$ \\
\hline Combined operations, $n(\%)$ & $6(17)$ \\
\hline Coronary bypass graft & $1(3)$ \\
\hline Mitral valve repair & $3(9)$ \\
\hline Aortic arch intervention & $2(6)$ \\
\hline Leaflet plication & $17(49)$ \\
\hline Mean cardiopulmonary bypass time (min), mean $\pm S D$ & $122.8 \pm 18.8$ \\
\hline Mean aortic cross-clamp time (min), mean \pm SD & $105.2 \pm 14.3$ \\
\hline \multicolumn{2}{|l|}{ Number of sub-valvular annular stitches } \\
\hline BAV patients & 12 \\
\hline Mean number of stitches & 8.1 \\
\hline SD & \pm 0.9 \\
\hline Range & $7-10$ \\
\hline TAV patients & 23 \\
\hline Mean number of stitches & 6.3 \\
\hline SD & \pm 0.9 \\
\hline Range & $6-9$ \\
\hline
\end{tabular}

BAV: bicuspid aortic valve; SD: standard deviation; TAV: tricuspid aortic valve.

(Carestream Health Inc., Rochester, NY, USA) into commaseparated values and then entered into a dedicated Microsoft Excel 2016 Datasheet. All statistical analyses were then carried out on SPSS 22 (IBM, Armonk, NY, USA) running on Windows 10 Machine (Microsoft Inc. Redmond, WA, USA).

Descriptive statistics are indicated as absolute numbers and percentages for discrete variables, and as mean and standard deviation for continuous variables. Where appropriate, minimum and maximum limits are expressed too.

Comparison of continuous measure was done via appropriate test, either paired measure $t$-test (for repeated measurements in the same subject before and after operation), the Mann-Whitney test or the Kruskal-Wallis test after evaluation of type of distribution of the population of values. $P$-values less than 0.05 indicated statistical significance.

The complete series of results are tabulated while the most relevant are also discussed in detail in the text, with $P$-values indicated contextually.

\section{RESULTS}

\section{Preoperative aortic annulus shape}

Preoperative CT scans showed a trend towards a larger aortic annulus in BAVs than in TAVs, in terms of perimeter $(P)(99.1 \pm 10.1$ vs $90.5 \pm 10.1 \mathrm{~mm}$; mean difference $+9 \%, P$-value 0.39$)$ and area (A) $\left(735.7 \pm 190.3\right.$ vs $590.6 \pm 136.8 \mathrm{~mm}^{2}$; mean difference $+24 \%$, $P$-value 0.14), although differences did not reach statistical 
Table 3: Preoperative diastolic measurements of the aortic annulus: TAVs versus type 1 BAVs versus type 0 BAVs analysis

\begin{tabular}{|c|c|c|c|c|}
\hline Parameters $(n=35)$ & TAVs $(n=23)$, mean \pm SD & Type 1 BAVs $(n=8)$, mean \pm SD & Type 0 BAVs $(n=4)$, mean \pm SD & $P$-value \\
\hline $\mathrm{MD}(\mathrm{mm})$ & $30.5 \pm 3.7$ & $34.2 \pm 4.3$ & $29.05 \pm 3.7$ & 0.04 \\
\hline $\mathrm{md}(\mathrm{mm})$ & $23.9 \pm 2.8$ & $29.5 \pm 3.9$ & $27.03 \pm 3.7$ & $<0.01$ \\
\hline Perimeter (mm) & $90.5 \pm 10.1$ & $103.6 \pm 12.5$ & $89.9 \pm 11.1$ & 0.02 \\
\hline Area $\left(\mathrm{mm}^{2}\right)$ & $590.6 \pm 136.8$ & $803.09 \pm 182.8$ & $601.1 \pm 149.9$ & 0.01 \\
\hline $\mathrm{El}$ (EI-MD/md ratio) & $1.3 \pm 0.1$ & $1.2 \pm 0.1$ & $1.1 \pm 0.1$ & $<0.01$ \\
\hline
\end{tabular}

BAV: bicuspid aortic valve; El: Ellipticity Index; MD: major diameter; md: minor diameter; SD: standard deviation; TAV: tricuspid aortic valve.

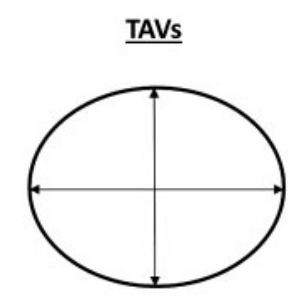

$\mathrm{MD}, \mathrm{mm}=30.6 \pm 3.7$ $\mathrm{md}, \mathrm{mm}=24.0 \pm 2.8$

$\mathrm{P}, \mathrm{mm}=90.5 \pm 10.1$

A, $\mathrm{mm}^{2}=590.6 \pm 136.8$

$\mathrm{EI}, \mathrm{MD} / \mathrm{md}$ ratio $=1.3 \pm 0.1$

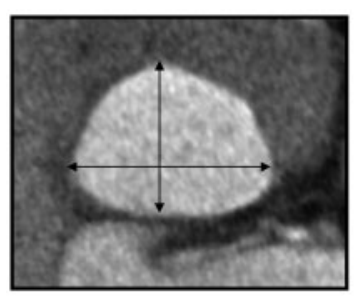

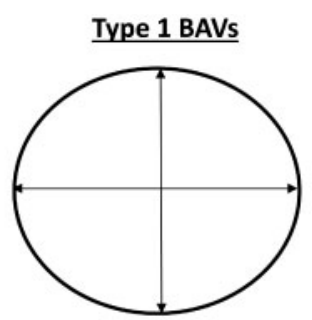

$\mathrm{MD}, \mathrm{mm}=34.3 \pm 4.3$ $\mathrm{md}, \mathrm{mm}=29.6 \pm 4.0$

$\mathrm{P}, \mathrm{mm}=103.7 \pm 12.6$

A, $\mathrm{mm}^{2}=803.1 \pm 182.9$

$\mathrm{El}, \mathrm{MD} / \mathrm{md}$ ratio $=1.2 \pm 0.1$

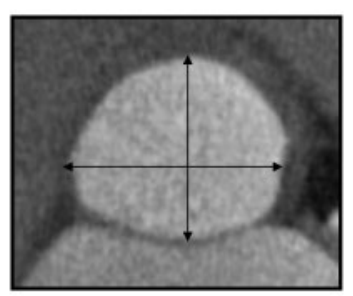

Type 0 BAVs

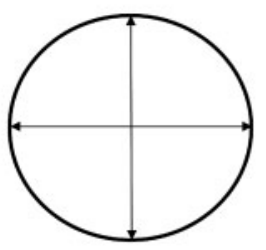

$\mathrm{MD}, \mathrm{mm}=29.0 \pm 3.7$ $\mathrm{md}, \mathrm{mm}=27.0 \pm 3.8$

$\mathrm{P}, \mathrm{mm}=90.0 \pm 11.1$

A, $\mathrm{mm}^{2}=601.1 \pm 150.0$

$\mathrm{El}, \mathrm{MD} / \mathrm{md}$ ratio $=1.1 \pm 0.1$

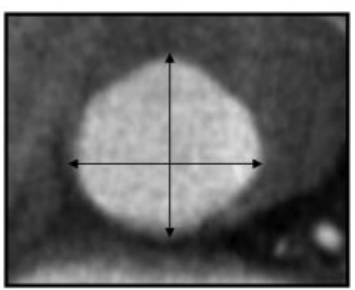

Figure 1: Preoperative diastolic measurements of aortic annulus: TAVs versus type 1 BAVs versus type 0 BAVs. BAV: bicuspid aortic valves; El: Ellipticity Index; MD: major diameter; md: minor diameters; TAV: tricuspid aortic valves.

significance. TAVs were characterized by an elliptical shape as compared to the more circular shape of the overall BAVs (El $1.3 \pm 0.1$ vs $1.1 \pm 0.1$; mean difference $-12 \%, P<0.01$ ), with a significant difference in the minor diameter $(23.9 \pm 2.8$ vs $28.7 \pm 3.4$; mean difference $+20 \%, P<0.01$ ) .

When analysing the subgroups of type 0 BAVs and type $1 \mathrm{BAV}$, and comparing them to the TAVs, CT scan data showed that the shape of type 0 BAVs was perfectly circular $(1.1 \pm 0.1)$, while type 1 BAVs lay in an intermediate spectrum with a more circular annulus compared to TAVs, but not perfectly round as type 0 BAVs $(1.2 \pm 0.1, P<0.01)$, suggesting a possible gradual range of circularity from TAVs, to type 1 BAVs to type 0 BAVs (Table 3).

Figure 1 shows the gradual trend towards circularity, both in a representative scheme and in CT scan images.

\section{Postoperative modifications of the aortic annulus after the aortic valve reimplantation procedure}

Postoperative CT scans did not show any significant difference in the annular shape between TAVs and overall BAVs (El $1.1 \pm 0.1$ vs $1.1 \pm 0.04$; mean difference $-0.5 \%, P$-value 0.76 ), suggesting a similar roundness of the 2 postoperative groups, which obviated the preoperative differences.
Nevertheless, the aortic annulus of overall BAVs preserved their larger dimensions compared to TAVs, even if reduced by the aortic valve reimplantation ( $P$ 90.7 \pm 7.3 vs $84.5 \pm 7.1 \mathrm{~mm}$; mean difference $+7 \%$, $P$-value 0.02 . A $632.3 \pm 123.6$ vs $535.3 \pm 97.5 \mathrm{~mm}^{2}$; mean difference $+18 \%$, P-value 0.01 ) (Table 4).

\section{Preoperative to postoperative variations in the aortic annulus after the aortic valve reimplantation procedure}

Comparing preoperative CT scans with the postoperative ones, we observed a mean area reduction of $9 \%$ in TAVs and $14 \%$ in overall BAVs, with the difference between the 2 reductions not proving significant ( $P$-value 0.14$)$. The El was reduced by $12 \%$ in TAVs and only $5 \%$ in BAVs, mostly due to type 1 BAVs $(P<0.01)$ (Table 5).

\section{Postoperative expansibility of the aortic annulus during the cardiac cycle}

The annular area expansibility, between systolic and diastolic sequences, assessed by postoperative CT scans of all patients, was only $1 \%$ (P-value 0.15 ) (Table 6). 
Table 4: Postoperative diastolic measurements of the aortic annulus: TAVs versus overall BAVs analysis

\begin{tabular}{|c|c|c|c|c|}
\hline Parameters $(n=35)$ & TAVs $(n=23)$, mean \pm SD & BAVs $(n=12)$, mean \pm SD & Mean difference (\%) & $P$-value \\
\hline $\mathrm{MD}(\mathrm{mm})$ & $27.4 \pm 2.4$ & $29.7 \pm 3$ & $+2.2(+8)$ & 0.02 \\
\hline $\mathrm{md}(\mathrm{mm})$ & $25.3 \pm 2.3$ & $27.6 \pm 2.8$ & $+2.2(+9)$ & 0.01 \\
\hline Perimeter (mm) & $84.5 \pm 7.1$ & $90.7 \pm 7.3$ & $+6.1(+7)$ & 0.02 \\
\hline Area $\left(\mathrm{mm}^{2}\right)$ & $535.3 \pm 97.5$ & $632.3 \pm 123.6$ & $+96.9(+18)$ & 0.01 \\
\hline $\mathrm{EI}$ (EI-MD/md ratio) & $1.1 \pm 0.1$ & $1.1 \pm 0.04$ & $-0.006(-0.5)$ & 0.76 \\
\hline
\end{tabular}

BAV: bicuspid aortic valve; El: Ellipticity Index; MD: major diameter; md: minor diameter; SD: standard deviation; TAV: tricuspid aortic valve.

Table 5: Preoperative to postoperative variations in diastolic parameters

\begin{tabular}{|c|c|c|c|}
\hline $\begin{array}{l}\text { Preoperative to postoperative variations } \\
\text { in diastolic parameters }(n=35)\end{array}$ & $\operatorname{TAV}(\%)(n=23)$ & $\operatorname{BAV}(\%)(n=12)$ & $P$-value \\
\hline $\mathrm{MD}(\mathrm{mm})$ & $-3.1(-10)$ & $-2.8(-9)$ & 0.69 \\
\hline $\mathrm{md}(\mathrm{mm})$ & $+1.4(+6)$ & $-1.1(-4)$ & 0.01 \\
\hline Perimeter (mm) & $-5.9(-6.5)$ & $-8.4(-8)$ & 0.35 \\
\hline Area $\left(\mathrm{mm}^{2}\right)$ & $-55.2(-9)$ & $-103.4(-14)$ & 0.14 \\
\hline El (El-MD/md ratio) & $-0.14(-12)$ & $-0.05(-5)$ & $<0.01$ \\
\hline
\end{tabular}

BAV: bicuspid aortic valve; El: Ellipticity Index; MD: major diameter; md: minor diameter; TAV: tricuspid aortic valve.

Table 6: Postoperative variations in aortic annulus expansibility during the cardiac cycle: overall patient analysis

\begin{tabular}{|c|c|c|c|c|}
\hline Postoperative parameters $(n=18)$ & Diastole $(n=18)$, mean \pm SD & Systole $(n=18)$, mean \pm SD & Mean variation (\%) & $P$-value \\
\hline $\mathrm{MD}(\mathrm{mm})$ & $29.0 \pm 2.7$ & $28.9 \pm 2.5$ & $-0.1(0.2)$ & 0.81 \\
\hline $\mathrm{md}(\mathrm{mm})$ & $27.0 \pm 2.4$ & $27.4 \pm 2.1$ & $+0.4(+2)$ & 0.12 \\
\hline Perimeter (mm) & $88.8 \pm 7.4$ & $89.5 \pm 7.1$ & $+0.7(+1)$ & 0.35 \\
\hline Area $\left(\mathrm{mm}^{2}\right)$ & $596.4 \pm 107.6$ & $605.6 \pm 96.6$ & $+9.1(+1)$ & 0.15 \\
\hline $\mathrm{El}$ (El-MD/md ratio) & $1.1 \pm 0.1$ & $1.0 \pm 0.04$ & $-0.02(-2)$ & 0.02 \\
\hline
\end{tabular}

BAV: bicuspid aortic valve; El: Ellipticity Index; MD: major diameter; md: minor diameter; SD: standard deviation; TAV: tricuspid aortic valve.

By comparing the variations in the preoperative annular area between TAVs and overall BAVs, we observed that, unlike TAVs, the expansibility was completely absent in BAVs, suggesting a possible loss of elasticity, potentially due to the larger size preoperatively (A: mean variation TAVs $+5 \%$ vs BAVs $-0.3 \%, P$-value $0.25)$. However, the difference in expansibility did not reach statistical significance. Instead, in the postoperative phase, both TAVs and BAVs show a small but similar expansibility of the aortic annulus after the annular reduction (A: mean variation TAVs $+3 \%$ vs BAVs $+2 \%$, P-value 0.99).

\section{DISCUSSION}

This study documents the role of aortic valve reimplantation procedures on shape, dynamism and geometry of the aortic annulus, with different results in case of BAVs or TAVs.

In TAVs, preoperative CT scans have shown an elliptical shape that was forced into a circular shape after the aortic valve reimplantation procedure, as demonstrated by the postoperative CT scans, indicating that the aortic annuloplasty with the Dacron graft had probably an active reshaping role on the annular geometry, without causing aortic cusp distortion.

Rankin et al. have already assessed a similar concept. In fact, by using a refined model of hemispheric aortic valve leaflets nested within a cylindric aorta, mathematical studies and CT angiography analysis, they demonstrated, for the first time in awake humans, that the normal human TAV had an elliptical structure [9].

Based on this principle, they created a device designed to permanently restore the physiological annular geometry during aortic valve repair into a fixed structure (HAART 300-Biostable Science \& Engineering, Inc., Austin, TX, USA). The device is based on the concept that the permanent restoration of the normal annular shape will facilitate the quality of aortic valve repair in midand long-term follow-up [15].

By observing the preoperative data, we found that BAVs have a mean larger annular size, in terms of area and perimeter, as compared to TAVs. This preprocedural anatomical finding might probably explain not only the greater mean area reduction of 


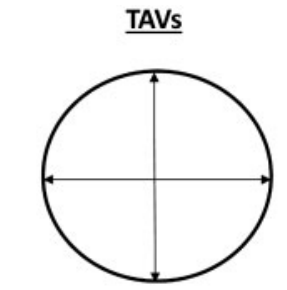

$\mathrm{MD}, \mathrm{mm}=27.4 \pm 2.5$

$\mathrm{md}, \mathrm{mm}=25.4 \pm 2.3$

$\mathrm{P}, \mathrm{mm}=84.5 \pm 7.1$

A, $\mathrm{mm} 2=53.4 \pm 97.5$

$\mathrm{El}, \mathrm{MD} / \mathrm{md}$ ratio $=1.1 \pm 0.1$

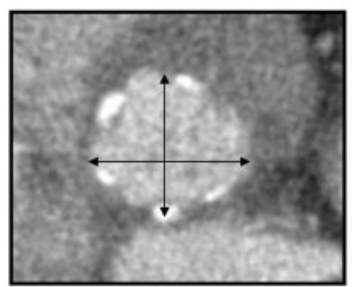

Type 1 BAVs

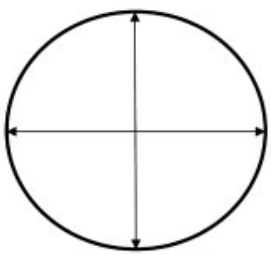

$\mathrm{MD}, \mathrm{mm}=31.1 \pm 3.1$

$\mathrm{md}, \mathrm{mm}=28.6 \pm 2.9$

$\mathrm{P}, \mathrm{mm}=93.9 \pm 8.3$

A, $\mathrm{mm} 2=689.8 \pm 124.4$

$\mathrm{El}, \mathrm{MD} / \mathrm{md}$ ratio $=1.1 \pm 0.1$

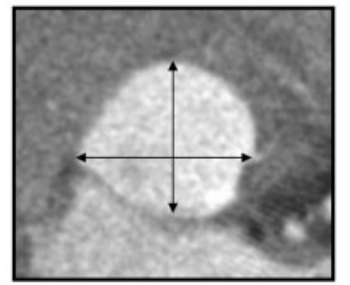

Type 0 BAVs

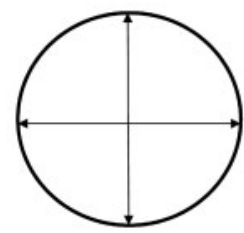

$\mathrm{MD}, \mathrm{mm}=26.8 \pm 3.1$

$\mathrm{md}, \mathrm{mm}=25.6 \pm 2.6$

$\mathrm{P}, \mathrm{mm}=84.3 \pm 7.6$

A, $\mathrm{mm} 2=517.4 \pm 115.6$

$\mathrm{El}, \mathrm{MD} / \mathrm{md}$ ratio $=1.0 \pm 0.1$

Figure 2: Postoperative diastolic measurements of aortic annulus: TAVs versus type 1 BAVs versus type 0 BAVs. BAV: bicuspid aortic valves; El: Ellipticity Index; MD: major diameter; md: minor diameters; TAV: tricuspid aortic valves.

BAVs observed in the postoperative phase (14\% vs $9 \%)$ but also the lack of expansibility already present preoperatively $(-0.3 \%$ vs $5 \%)$, suggesting a possible loss of active elasticity.

Furthermore, we found that BAVs had an unexpected behaviour: in type 0 BAVs: the preoperative CT scans revealed a circular shape of the aortic annulus which was preserved even after the aortic reimplantation as demonstrated by the postoperative $\mathrm{CT}$ scans. Surprisedly, type 1 BAVs revealed an intermediate behaviour between TAVs and type 0 BAVs, with a native elliptic shape, less pronounced as compared to TAVs. Thus, in the postoperative phase, both TAVs and all types of BAVs had a circular shape reversing the preoperative differences (postoperative El: TAVs $=1.1$ vs BAVs 1.1, with a preoperative to postoperative El variation of about $12 \%$ in TAVs and about $5 \%$ in overall BAVs, mostly due to type $1 \mathrm{BAVs}$ ).

The native shape of the BAVs is still a matter of debate. Rankin et al. [10] described the usual annular anatomy of BAVs as elliptical, with the sinus-to-sinus diameter being larger. Based on the same principle of TAVs, they created a novel bicuspid annuloplasty ring (HAART 200-Biostable Science \& Engineering, Inc., Austin, TX, USA) with a circular base geometry to obtain an annular reduction and reshaping to a symmetric circular geometry that could facilitate leaflet repair and cusp coaptation.

On the contrary, Philip et al. [11] demonstrated that patients with severe aortic stenosis due to BAV had an aortic annulus significantly less elliptical (EI $1.2 \pm 0.1$ vs $1.3 \pm 0.1, P<0.01$ ) and more circular $(39 \%$ vs $4 \%, P<0.01)$ compared to the TAV annulus, confuting the traditional exclusion criterion of BAV for transcatheter aortic valve replacement due to the asymmetric anatomy of the BAV annulus. Our possible explanation to this incongruity of data is the type of BAV: type $1 \mathrm{BAVs}$ have a native intermediate behaviour between TAVs (elliptical shape) and type 0 BAVs (circular shape), suggesting that the presence of a complete or incomplete raphe and the spatial position of cusps might influence the difference in annular shape between the 2 subgroups of BAVs. This aspect might be explained by a possible gradual spectrum of circularity from TAVs, to type $1 \mathrm{BAVs}$ to type 0 BAVs (Fig. 1).
Nonetheless, after aortic valve reimplantation, all valve types assume a circular form, suggesting the active role of the annuloplasty by the Dacron graft (Fig. 2). In fact, the annuloplasty seems to restore a symmetric geometry of the aortic annulus regardless of the native morphology, assuring the expected reduction in aortic annulus size. Overall, the annuloplasty did not influence the normal functioning of the valve, even though a cusp plication was more frequently necessary to compensate for a cusp prolapse induced by the reduction in root diameter.

The subgroup of 18 patients underwent pre- and postoperative ECG-gated CT scan, both in systolic and in diastolic sequences, which allowed variations in annular expansibility during the cardiac cycle to be evaluated. The preoperative analysis showed, unlike TAVs, a complete inelasticity of BAVs, which was then partly restored in the postoperative phase after the aortic annular reduction, becoming comparable to expansibility of TAVs.

\section{Limitations}

Due to the small size of the patient subgroups used, variations in annular expansibility should be considered with caution. These data need to be confirmed by a larger number of patients to evaluate a possible spectrum of ellipticity between BAVs and TAVs.

\section{CONCLUSIONS}

This study confirms the expected reduction in aortic annulus size following the reimplantation procedure. The annulus in TAVs was forced from a native elliptical to a circular shape. It was preserved in type 0 BAV where it maintained an almost perfect circular shape. Type 1 BAVs seem to lie in a spectrum between the previous ones, also becoming circular after the reimplantation. 
The preoperative annular expansibility was completely absent in BAVs. In the postoperative phase it was small and similar to TAVs.

Conflict of interest: none declared.

\section{REFERENCES}

[1] Aicher D, Fries R, Rodionycheva S, Schmidt K, Langer F, Schäfers HJ. Aortic valve repair leads to a low incidence of valve-related complications. Eur J Cardiothorac Surg 2010;37:127-32.

[2] Navarra E, El Khoury G, Glineur D, Boodhwani M, Van Dyck M, Vanoverschelde J-L et al. Effect of annulus dimension and annuloplasty on bicuspid aortic valve repair. Eur J Cardiothorac Surg 2013;44:316-22.

[3] Lansac E, Di Centa I, Bonnet N, Leprince P, Rama A, Acar C et al. Aortic prosthetic ring annuloplasty: a useful adjunct to a standardized aortic valve-sparing procedure? Eur J Cardiothorac Surg 2006;29:537-44.

[4] Aicher D, Schneider U, Schmied W, Kunihara T, Tochii M, Schäfers HJ. Early results with annular support in reconstruction of the bicuspid aortic valve. J Thorac Cardiovasc Surg 2013;145:S30-4.

[5] Schöllhorn J, Rylski B, Beyersdorf F. Aortic valve annuloplasty: new single suture technique. Ann Thorac Surg 2014;97:2211-13.

[6] Lansac E, Di Centa I, Sleilaty G, Crozat EA, Bouchot O, Hacini R et al. An aortic ring: from physiologic reconstruction of the root to a standardized approach for the aortic valve repair. J Thorac Cardiovasc Surg 2010;140: S28-35.
[7] David TE, Feindel CM, David CM, Manlhiot C. A quarter of a century of experience with aortic valve-sparing operations. J Thorac Cardiovasc Surg 2014;148:879-80

[8] De Paulis R, Chirichilli I, Scaffa R, Weltert L, Maselli D, Salica A et al. Long-term results of the valve reimplantation technique using a graft with sinuses. J Thorac Cardiovasc Surg 2016;151:112-19.

[9] Rankin JS, Bone MC, Fries PM, Aicher D, Schäfers HJ, Crooke PS. A refined hemispheric model of normal human aortic valve and root geometry. J Thorac Cardiovasc Surg 2013;146:103-8.

[10] Mazzitelli D, Pfeiffer S, Rankin JS, Fischlein T, Choi YH, Wahlers T et al. A regulated trial of bicuspid aortic valve repair supported by geometric ring annuloplasty. Ann Thorac Surg 2015;99:2010-16.

[11] Philip F, Faza NN, Schoenhagen P, Desai MY, Tuzcu EM, Svensson LG et al. Aortic annulus and root characteristics in severe aortic stenosis due to bicuspid aortic valve and tricuspid aortic valves: implications for transcatheter aortic valve therapies. Catheter Cardiovasc Interv 2015;86: E88-98.

[12] Sievers $\mathrm{HH}$, Schmidtke C. A classification system for the bicuspid aortic valve from 304 surgical specimens. J Thorac Cardiovasc Surg 2007;133: 1226-33.

[13] De Paulis R, De Matteis GM, Nardi P, Scaffa R, Colella DF, Bassano C et al. One-year appraisal of a new aortic root conduit with sinuses of Valsalva. J Thorac Cardiovasc Surg 2002;123:33-9.

[14] De Paulis R, De Matteis GM, Nardi P, Scaffa R, Colella DF, Chiarello L. A new aortic conduit for surgical treatment of aortic root pathology. Ital Heart J 2000;1:457-63.

[15] Mazzitelli D, Nöbauer C, Rankin JS, Badiu CC, Krane M, Crooke PS et al. Early results after implantation of a new geometric annuloplasty ring for aortic valve repair. Ann Thorac Surg 2013;95:94-7. 